\title{
SINTAXE, SEMÂNTICA E FORMALIZAÇÃO
}

\author{
SYNTAX, SEMANTICS AND FORMALIZATION
}

Adriano Marques da Silva *

Resumo: O presente artigo aborda o seguinte problema: qual o formato e o escopo de uma teoria semântica formal adequada à descrição e explicação dos fenômenos semânticos presentes nas línguas naturais? A primeira seção expõe princípios fundamentais para uma semântica das línguas naturais, face às críticas do Contextualismo. A segunda seção expõe as principais características do programa de investigação proposto por P.M. Pietroski. Por fim, é apresentada uma breve avaliação desse programa à luz dos critérios apresentados nas seções anteriores. Argumento que esse programa possui virtudes metodológicas consideráveis, pois adota como explanandum generalizações empíricas substanciais, fenômenos sintáticos que precisam ser explicados. Trata-se, portanto, de uma proposta que não se limita a descrever as intuições dos falantes e codificá-las em notação lógico-matemática.

Palavras-chaves: Semântica Clássica; Interface sintaxesemântica; Forma Lógica; Contextualismo; Gerativismo.

Abstract: This article addresses the following problem: which is the format and scope of a formal semantic theory adequate to the description and explanation of semantic phenomena present in natural languages? The first section exposes the main principles for a semantics of natural languages, given the criticisms of Contextualism. The second section presents the main features of the research program proposed by P.M. Pietroski. Finally, it is presented a brief evaluation of this program inthe light of the criteria presented in the previous

* Mestre em Filosofia pela UFRN. Doutorando do Programa Integrado de Doutoradoem Filosofia UFRN-UFPB-UFPE.m@il: adrymarques@gmail.com. 
sections. I argue that this program has considerable methodological virtues, because it adopts as explanandumsubstantial empirical generalizations, syntactic phenomena which must be explained. It is therefore a proposal that does not merely describe the intuitions of speakers and encode them in logical-mathematical notation.

Keywords: Classical semantics; Syntax-semantics Interface; Logical Form; Contextualism; Generativism.

\section{Introdução}

O que a semântica estuda? Como definir seu objeto de estudo? Responder essas perguntas não é uma tarefa simples, pois não há consenso entre os semanticistas sobre como descrever e explicar os fenômenos semânticos presentes nas línguas naturais. A pluralidade de modelos semânticos fornece um indício do dissenso. É possível dividir as abordagens semânticas em três grandes grupos: semântica formal, semântica argumentativa e semântica cognitiva. Neste ensaio, tratarei apenas da primeira. Então, nossa pergunta reduz-se à pergunta (aparentemente) mais simples:

(P) Qual o objeto de estudo da semântica formal?

Mais especificamente:

(P1) Qual o formato e escopo de uma semântica formal adequada à descrição e explicação do significado em linguagem natural?

Acredito que uma teoria semântica, seja ela formal ou não, deve obedecer a dois critérios mínimos, critérios necessários, mas não suficientes, para que possa ser caracterizada como uma teoria linguística. São eles: 
(C1) Adequação empírica: Uma teoria semântica deve formular regras capazes de justificar, de forma sistemática, propriedades e relações semânticas. Entre as propriedades, incluem-se significado, ambiguidade, polissemia, anomalia etc. Quanto às relações, estão incluídas tanto relações lógico-semânticas, como contradição, acarretamento, sinonímia etc., quanto relações temáticas, tais como origem, objetivo, localização, instrumento etc.;

(C2) Correção formal: Uma teoria semântica deve ser sistemática e precisa. Deve postular uma metalinguagem capaz de traduzir os fenômenos linguísticos em uma representação simbolicamente manipulável.

Como explica Pires de oliveira (2009), 'formal' é um meta-termo que se encontra associado a pelo menos três noções:

(i) Formal como científico;

(ii) Formal como sinônimo de autônomo;

(iii) Formal relacionado a cálculo.

Os critérios (C1)-(C2) exigem que uma teoria semântica, enquanto teoria linguística, deve ser formal ou potencialmente formalizável (acepção (iii)). Essa última acepção de formal é pressuposta quando se usa o termo 'semântica formal'. Além disso, é comumente utilizada para designar certa tradição, a saber, a tradição semântico-formal da filosofia da linguagem. Embora acredite na necessidade de um aparato técnico para o estudo das línguas naturais, também creio que isso não equivale a admitir que tal aparato deva, necessariamente, coincidir ou restringir-se aos recursos da lógica-matemática. P. M. Pietroski oferece uma alternativa interessante: partindo de uma perspectiva gerativista, ele sugere a adaptação do aparato formal disponível nas teorias sintáticas aos recursos de uma teoria 
semântica formal mínima, semi-composicional. Ou seja, adotando uma perspectiva formal na acepção (ii) (uma vez que o gerativismo postula a autonomia da sintaxe), esse autor propõe a construção de uma teoria semântica formal, na acepção (iii). Essa teoria serviria como um dispositivo técnico mais adequado ao estudo dos fenômenos semânticos (i.e, seria formal na acepção (i)).

A partir desse quadro teórico, abordarei a questão $(\mathrm{P})$ e apresentarei a resposta de Pietroski à pergunta (P1). Para tanto, este ensaio está dividido nas seguintes seções: na seção 1 é apresentada uma breve exposição da semântica formal clássica e os princípios para uma semântica das línguas naturais, face às críticas do contextualismo. $\mathrm{Na}$ seção 2, é oferecida uma exposição do programa proposto por Pietroski. Na seção 3 é apresentada uma avaliação desse programa, à luz dos critérios expostos nas seções anteriores.

\section{A semântica clássica e o contextualismo}

Os problemas e controvérsias que dizem respeito à análise semântica das línguas naturais provêm do conflito, nem sempre declarado, entre o emprego do aparato lógico-matemático para a arregimentação e/ou descrição da linguagem natural. Mais importante ainda, esse conflito parece ser a origem remota de certa interpretação, predominante nos dias de hoje em Filosofia da Linguagem, segundo a qual muitos problemas semânticos acumulados pela filosofia analítica de tradição lógico formal, tradição predominante durante o início do século XX foram resolvidos ou mesmo dissolvidos com a virada pragmática (Taylor, 1985) deflagrada a partir da segunda metade do século XX. Com efeito, desde então tem havido uma perceptível transformação na filosofia analítica da linguagem, a saber: a 
perspectiva lógico-formal de análise da linguagem natural, cede lugar ao estudo de fenômenos pragmáticos (como o estudo dos atos de fala ou implicatura conversacional). No mais recente debate em filosofia da linguagem temos uma nova edição da disputa entre abordagens formais e abordagens pragmáticas. De um lado da disputa temos os minimalistas semânticos (como Ernest Lepore e Herman Cappelen) que defendem que a tradição semântico-formal da filosofia da linguagem carece tão somente de alguns ajustes pontuais, periféricos. Do outro lado, temos os contextualistas (como François Recanati e Julius Moravcsik), segundo os quais enunciações em linguagem natural sofrem a influência de processos pragmáticos que não só afetam como determinam o conteúdo enunciativo de qualquer sentença. O minimalismo propõe uma reforma da lógica formal para a representação da semântica das línguas naturais, enquanto o contextualismo critica os fundamentos que conduzem o empreendimento da semântica formal aplicado a línguas naturais.

Seguindo a caracterização sugerida por Cappelen e Lepore (2005), podemos identificar diferentes versões do contextualismo, uma gradação que vai do menos ao mais radical. Ou seja, temos versões ortodoxas, radicais e versões heterodoxas, menos robustas. O contextualismo radical, segundo os autores, equivale à conjunção das seguintes teses:

(CR1) Nenhuma oração em linguagem natural expressa semanticamente uma proposição, isto é, tem o valor semântico de uma proposição;

(CR2) Toda oração em linguagem natural expressa semanticamente apenas um conteúdo sub proposicional;

(CR3) Apenas uma enunciação (utterance) de uma oração em linguagem natural pode expressar semanticamente uma proposição e pode ter condições de verdade. 
Essa caracterização, segundo os autores, representa uma versão radical de contextualismo, pois sustenta que todas as expressões em linguagem natural variam de acordo com o contexto de sua enunciação. Cappelen e Lepore definem o contextualimo moderado como uma versão atenuada do contextualismo. Nessa versão moderada temos a conjunção das seguintes teses:

(CM1) O conteúdo semântico de algumas expressões que não são membros do conjunto dos indexicais óbvios varia de acordo com o contexto de sua enunciação;

(CM2) Nem todas as orações da linguagem natural expressam semanticamente proposições ou têm condições de verdade;

(CM3) Apenas as enunciações de orações semanticamente incompletas expressam uma proposição e têm condições de verdade.

Entre as expressões semanticamente sensíveis ao contexto estariam segundo o contextualismo moderado, estão:

(a) Adjetivos comparativos ('alto', 'rico' etc.);

(b) Quantificadores (em expressões como 'todos os alunos', 'nenhuma pessoa' etc.);

(c) Atribuições epistêmicas ('João sabe que a terra é redonda' etc.);

(d) Atribuições morais ('bom', 'mal', 'permissível' etc.);

(e) Clime reports ('chove', 'neva' etc.)

Quer me parecer que as que as críticas do contextualismo ao minimalismo semântico são justas. E mais, parecem coerentes com o que se sabe atualmente sobre os aspectos gerais da cognição linguística ${ }^{1}$. Sabe-se que as línguas naturais possuem características idiossincráticas, e todas elas são perpassadas por ambiguidades lexicais, sintáticas e fonológicas. 
A performance línguística depende de um sistema de fonação e articulação que não são perfeitamente integrados. Como as línguas não são sistemas perfeitos comunicação, elas precisam ser assessoradas por vários recursos extra-linguísticos. Essas constatações não afetam diretamente o empreendimento da semântica formal, pois um semanticista não é obrigado a admitir que as línguas naturais sejam sistemas lógicos. Esses últimos são utilizados como uma metalinguagem técnica, cujas propriedades o semanticista conhece bem, a partir da qual hipóteses, descrições e explicações podem ser expressas e empiricamente avaliadas. Contudo, tais constatações impõem problemas significativos à modelagem formal. Ou melhor, trazem problemas teóricos fundamentais sobre delimitação do escopo e limites desse tipo de empreendimento.

Creio que a descrição sintática do sistema linguístico é um requisito imprescindível à elaboração de teorias semânticas. Isso por um motivo muito simples: o semanticista, ao examinar um fenômeno de uma língua natural, não pode se dar o luxo de postular uma sintaxe. Ele tem que respeitar as características estruturais da língua que está analisando. Em suma, a descrição estrutural não pode ser estipulada, tem que ser descoberta. Chomsky (1965) já demonstrara ceticismo em relação à formulação de uma teoria semântica independente da teoria gramatical. Isso não significa que a semântica é 'redutível' a sintaxe, mas sim que fazer semântica é uma forma de fazer (simultaneamente) sintaxe.

O contextualismo implica a dissolução do estudo semântico formal das línguas naturais? Não é esse o caso. Como afirma Leclerc (2009, p. 18) "Os princípios de composicionalidade e contexto não precisam ser abandonados, mas devem ser aplicados com cuidado". O autor sugere princípios para uma teoria semântica que, segundo o contextualismo, seriam mais adequados para modelar e investigar nossas habilidades linguísticas. São eles²: 
(A) Ter um conteúdo vero-condicional determinado ou expressar uma proposição determinada é uma propriedade de um ato-de-enunciação-num-contextodeterminado, e não uma propriedade de uma frase-tipo;

(B) $\mathrm{O}$ significado literal não determina rigorosamente o que é dito pela enunciação de uma frase, mas sim determina um leque de possibilidades que só o contexto pode restringir e determinar;

(C) $\mathrm{O}$ que é dito é determinado apenas parcialmente pelo significado (ou potencial semântico);

(D) A teoria do significado não deve ser tratada independentemente da teoria da compreensão linguística;

(E) Aplicamos sempre significados não específicos a contextos específicos.

Retornarei a esses princípios posteriormente. De posse deles, parece pertinente formular a seguinte questão: qual o melhor candidato para superar as dificuldades metodológicas decorrentes da aceitação das críticas contextualistas? Mais precisamente:

(P2) Como formular regras capazes de sistematizar fenômenos de alta dependência contextual? Em que medida é possível incorporar as críticas contextualistas em uma teoria semântica formal?

Quer me parecer que a resposta exata a essa pergunta se dá pela apresentação efetiva de um aparato formal, o que só pode ocorrer no curso da investigação de fenômenos semânticos específicos. No que se segue, farei uma exposição da teoria semântica de Pietroski. Ou melhor, de sua proposta de reconceitualização da semântica formal a partir de uma perspectiva chomskiana. Em que medida ela é coerente com os princípios (A)-(E)? 


\section{Pietroski e a interface sintaxe-semântica}

\subsection{Gerativismo e dados negativos}

Representante ilustre da abordagem lógico-formal em filosofia da linguagem, o programa davidsoniano para as línguas naturais parte de uma conjectura ousada, a saber: para cada língua natural (ou fragmento de língua natural) L, existe uma teoria da verdade que pode servir como uma teoria do significado adequada a L. Essa conjectura pode e é, efetivamente, aplicada no estudo das línguas naturais. Contudo, existem críticas não só quanto à adequação de certas soluções formais propostas por Davidson, mas, como foi visto críticas mais gerais a respeito da viabilidade desse tipo de empreendimento. Essas críticas provêm tanto do contextualismo em filosofia da linguagem, como do trabalho de Chomsky.

Pietroski procura apresentar um projeto que seja ao mesmo coerente com as críticas de Chomsky, mas que não abandone o aparato que a semântica formal oferece ao estudo das línguas naturais. Em Pietroski (2004), o autor procura explicar o que o gerativismo pode nos ensinar sobre a natureza do significado e sobre a natureza das teorias semânticas. A resposta oferecida pelo gerativismo é essencialmente negativa: ele nos ensina o que o significado não pode ser. Eliminando as alternativas improváveis ou impossíveis, restam algumas vias produtivas, que merecem atenção. Vejamos, a seguir, uma síntese de seu argumento.

Pietroski sustenta que dada a tese da autonomia da sintaxe e os vários argumentos sobre pobreza de estímulos, torna-se difícil manter certos pressupostos a respeito da semântica das línguas naturais. Especificamente, argumenta, parece difícil manter que existem teorias vero-condicionais para as línguas naturais. Ele destaca que existem teorias sobre propriedades intrínsecas às línguas naturais e que a semântica pode ser concebida nesses termos. Mais precisamente, ele 
defende que a semântica pode ser concebida como o estudo de características que restringem, mas não determinam, condições de verdade.

Essa me parece ser uma direção natural, uma vez admitida a autonomia da sintaxe, isto é, uma vez admitido que há um sistema cognitivo, biológico, que impõe restrições de interpretabilidade, restrições sobre como uma sequência linear de sons de uma língua é hierarquicamente organizada, pela nossa mente, em estruturas de constituintes. Essa estrutura hierárquica é governada por princípios muito específicos que não determinam o significado de uma sentença, mas impõe certas condições de inteligibilidade.

A perspectiva gerativista, acrescenta Pietroski, não se adapta a hipótese de que uma língua natural associa itens linguísticos a condições de verdade modelo-teoréticas, pois a língua-I impõe apenas algumas restrições de inteligibilidade. No limite, expõem o formato de construções possíveis, mas não realizáveis, nas línguas naturais. $\mathrm{O}$ dado negativo diz respeito, em suma, à relação entre sequências de palavras e sua inteligibilidade, entre som e significado. Segundo Pietroski, cabe explicar esses padrões. Existem duas modalidades de restrição:

(i) A Faculdade da Linguagem impõe restrições que são independentes de quaisquer limitações impostas por outros sistemas cognitivos;

(ii) A fonte dessas restrições dá-se na interface entre a Faculdade da Linguagem e outros sistemas cognitivos (percepção, conceptualização etc.).

Como exemplo do tipo (ii) de restrição, temos as restrições de processamento de sentenças encaixadas (há um limite, imposto pela memória de trabalho, no número de adjuntos que podem ser processados), cacófatos, estados de língua (interface entre o sistema computacional e o sistema articulatório) etc. Como exemplo de restrição do tipo (i), 
Pietroski oferece o seguinte:

(1) O senador telefonou para o milionário do Texas.

(2) O senador ligou para o milionário, e o milionário era do Texas.

(3) O senador ligou para o milionário, e a chamada foi (feita) do Texas.

(4) \# O senador chamou o milionário, e o senador era do Texas.

Temos aqui um dado negativo: a sentença (1) tem o significado indicado nas paráfrases (2) e (3), mas não na paráfrase (4). A estrutura de constituintes que dá origem a leitura (2) e (3) corresponde, respectivamente, a:

(1') $\{[\mathrm{O}$ senador] [telefonou [para [o milionário [do Texas]]]].\}.

(1") $\{[$ O senador] [[telefonou [para [o milionário]] [do Texas]]].\}.

Ou seja: em (1') 'do Texas' é adjunto do sintagma 'o milionário'; em (1'), ‘do Texas' é um adjunto do sintagma verbal 'telefonou para o milionário'. A ambiguidade em (1) é resultado de duas relações de escopo distintas, mas não três ou quatro ou quarenta. Esse exemplo indica que o fenômeno da ambiguidade admite gradações. É evidente que a ambiguidade de (1) é desfeita em contexto, mas podemos dizer que o fenômeno da ambiguidade estrutural não existe, que não é um fenômeno que requer explicação?

É possível ainda acrescentar que existem sentenças ininteligíveis, sentenças que não formam estruturas de constituintes, como em: 
(1) \# Para o telefonou o do milionário senador Texas.

Outro fenômeno, bastante conhecido na literatura gerativista, é a anáfora. Considere as seguintes sentenças:

(1) João disse que ele vai sair.

(2) Ele disse que João vai sair.

A sentença (2) é clara. Se perguntamos: quem ele disse que vai sair? A resposta é: João. Já em (1), se perguntamos: quem ele disse que vai sair? Será o João? Não é possível determinar.

Considere ainda as imposições categoriais e semânticas impostas pela natureza de itens lexicais, como os verbos a seguir:

(1) John is eager to please.

(2) Jonh is easy to please.

(3) John is eager that he please relevant parties.

(4) John is easy that relevant parties please him.

(5) \# John is eager that relevant parties please him.

(6) \#John is easy that he please relevant parties.

É possível ver, claramente, que há uma interação entre o significado dos itens lexicais e a estrutura argumental e temática que cada um deles impõe. Esses fatos delimitam, embora não determinem, o significado de 'eager' e 'easy'.

Os exemplos apresentados por Pietroski são, na verdade, uma pequena amostra de um padrão robusto, um resultado convergente, proveniente de várias linhas de pesquisa empírica nos últimos 50 anos: diferenças mínimas no padrão de concatenação de constituintes produzem consideráveis efeitos interpretativos. É importante destacar que os exemplos que Pietroski oferece não são utilizados como peça retórica para a 
confirmação de suas teses, mas são fenômenos presentes em todas as línguas naturais atualmente conhecidas.

Assim sendo, compete a uma teoria semântica responder perguntas do tipo: como os falantes não compreendem as línguas naturais? Por que as expressões não significam aquilo que elas não significam? O critério de sucesso adotado por Pietroski não é novo, mas é muito justo: uma teoria do significado é adequada se for capaz de fornecer uma descrição finita dos infinitos fatos semânticos manifestados em expressões linguísticas. Porém, segundo Pietroski, não é necessário assumir uma teoria da verdade substantiva para tratar dos fenômenos importantes à teoria semantica, a saber:

(i) A composicionalidade de constituintes sintáticos;

(ii) A combinação de itens lexicais.

Para esse empreendimento, acrescenta, não é necessário adotar o pressuposto de que a compreensão linguística reduz-se a regras de composição semântica, muito menos o pressuposto de que o significado de itens lexicais deve ser definido por teoremas à la Davidson. O que é necessário é descobrir o papel semântico dos vários itens linguísticos (itens lexicais e funcionais) e como as relações gramaticais (isto é, os modos de combinação gramatical) especificam, sem determinar, condições de verdade.

O que interessa, em suma, é explicar fenômenos teoricamente relevantes à teoria linguística e, em particular, relevantes à semântica das línguas naturais. Para Pietroski isso significa, por um lado, que não se deve inventar um novo expediente, uma linguagem mental, por exemplo, e então passar a tratar dela. Seria mudar de assunto, no fundo. Por outro lado, significa que não parece satisfatório responder que a faculdade da linguagem é responsável apenas pela sintaxe. Além da forma fonética e fonológica, a faculdade da linguagem é responsável 
pela geração de instruções para a criação de representações mentais complexas. Ademais, acrescenta, em linguagem natural conceitos são lexicalizados de maneiras bastante específicas, e eles interagem com o léxico por meio de restrições complexas. De fato, malgrado os princípios que regem a computação fonológica, sintática e semântica não sejam idênticos, a idéia fundamental da teoria chomskiana é que a informação fonética não pode ser processada em separado da informação categorial. Por exemplo, 'gato' é uma sequência traços fonéticos e corresponde a uma categoria sintática nominal; 'bato' é uma outra sequência de traços fonéticos, que corresponde a uma categoria sintática verbal.

Pietroski alerta que a Faculdade da Linguagem não deve ser tomada como a contraparte sintática de uma teoria semântica modelo-teorética. É tentador tomar sentenças geradas pela faculdade da linguagem como sentenças bem formadas de uma semântica, mas as não devemos fazê-lo pois, argumenta, a Língua-I que cada um de nós possui instanciada em nossas mentes não é idêntica. Existem idiossincrasias individuais, culturais, sociais.

O que Pietroski afirma, em outras palavras, é que uma teoria chomskiana do significado não deve ser uma mera reedição da idéia de que há uma associação entre a sentença $\mathrm{S}$ e o seu significado, [[S]], mediado por algum sofisticado algoritmo. Essa posição me parece sensata, pois é coerente com o programa gerativista, com suas assunções de base. Se a Língua-I é um procedimento algorítmico biologicamente instalado na mente humana, ela não pode ser identificada com um sistema lógico instanciado na mente dos falantes-ouvintes. Como qualquer outro órgão, ela está sujeita ao desenvolvimento, maturação etc. Sendo assim, quando nós dizemos que 'o' português brasileiro possui tais e quais características isso significa, a rigor, que certo conjunto de indivíduos, a partir de interações individuais com o ambiente, 
tem instanciado em suas mentes certas propriedades da Língua-I, um sistema internalizado que os permite produzir e compreender um número potencialmente infinito de sentenças. Parece ainda mais estranho dizer que esse algoritmo associa expressões linguísticas a coisas, relaciona linguagem e mundo.

Pietroski sustenta que é errado conceber uma semântica coerente com o gerativismo através da simples superposição da conjectura davidsoniana sobre os recursos da sintaxe gerativista. Ele admite que essa pode ser uma estratégia tecnicamente interessante, que pode ser útil à investigação empírica. Contudo, o semanticista deve ter em mente, alerta, que essa junção tem pouco realmente relacionado à noções como 'verdade' ou satisfazibilidade' etc. Em suma, é muito tendencioso conceber a faculdade da linguagem a partir de uma simples combinação formal, por melhores que sejam os aspectos técnicos oferecidos por esse tipo de formalismo. Apesar dessas críticas, Pietroski acredita que uma modesta tipologia davidsoniana é necessária (e, em alguns casos, imprescindível) à análise semântica, mas o semanticista não precisa crer que o modelo semântico por ele postulado associe sentenças a estados de coisas. Ou seja, a tipologia empregada em teorias semânticas não deve confundir o semanticista, levá-lo a crer que expressões linguísticas denotem valores semânticos de fato. O que está em questão é o tipo de formalismo que melhor se adapte a caracterização do formato da língua-I. É possível que existam dois estágios no processamento semântico:1.Processamento sintático; 2. Envio do input sintático para outras faculdades; Mas é possível que ocorra da seguinte forma: 1. Processamento sintático; 2. modulação contextual/variáveis eventivas ${ }^{3}$. Envio para outros módulos. Sabe-se muito pouco sobre isso. Me parece que essa é uma disputa ociosa, se encarada como puramente teórica. Tratase de uma questão empírica.

Como visto anteriormente, na seção 1 , o princípio (D) sugere um aspecto que deveria, necessariamente, ser levado em 
consideração em uma teoria semântica: a compreensão linguística não se reduz à calculabilidade. Penso que o projeto de Pietroski é coerente com esse princípio, pois sua abordagem não pressupõe que o significado em língua natural seja algoritmicamente determinado. Não obstante, ele reconhece a necessidade do emprego de uma metalinguagem técnica no estudo da semântica. Reconhece ainda que é possível aproveitar os insights e as inovações formais oferecidas por Davidson, desde que não se esteja comprometido a aderir a sua conjectura.

Se a semântica é tomada como um ramo dessa investigação naturalista, então ela se deparar com o problema metodológico central enfrentado pelo gerativismo: não existe um modelo animal que viabilize a metodologia de investigação neurofisiológica da linguagem sem a mediação de uma descrição abstrata da competência linguística. A investigação proposta por Pietroski parece estar estreitamente vinculada ao estudo de certas propriedades formais e estruturais. Também parece coadunar-se aos critérios $(\mathrm{C} 1)-(\mathrm{C} 2)$, pois é coerente ao princípio de que é necessário o emprego de uma metalinguagem técnica dotada de recursos necessários a abstração e simplificação adequada dos dados. A partir daí, os problemas podem ser parametrizados. É então posto em marcha um programa de investigação científica. Cumpre saber se as ferramentas à disposição são satisfatórias.

Chomsky transpõe a hipótese fregeana da composicionalidade para o domínio das línguas naturais. $\mathrm{O}$ modelo chomskiano toma de empréstimo a noção fulcral, apresentada por Frege, de que a análise semântica se compõe de predicado e argumento. Mas, ao contrário da proposta fregeana, no modelo gerativista, a notação predicado-argumento é generalizada, estendida a todos os constituintes sintáticos das sentenças. Outra diferença importante entre essas abordagens é que a abordagem gerativista atribui aos itens lexicais da linguagem natural (determinantes, sintagmas nominais, verbos, 
adjetivos etc.) certas exigências de ordem categorial (e semântica). Ou seja, os itens lexicais possuiriam uma natureza intrínseca, responsável por sua disposição hierárquica em estruturas de constituintes. Assim, um item lexical como 'amar', por exemplo, é um verbo que exige, necessariamente, dois argumentos, os quais devem atender a certas exigências categoriais, sintáticas. Por contraste, a análise estritamente lógica de uma língua natural dispensa a hipótese de que os constituintes dessa última possuem uma natureza determinada, específica. É comum que os lógicos construam uma linguagem formal a partir de um vocabulário gramatical não interpretado, não lógico. Ao traduzirmos o predicado 'amar' para a lógica de predicados de primeira ordem, por exemplo, podemos traduzi-lo como um predicado mono argumental cuja estrutura sintática assumida pode ser (1) ou (2):

(1) João [ama Maria]

(2) [João ama] Maria

Ou seja, do ponto de vista formal, o predicado 'ama' é uma relação, cujas características sintático-semânticas são convencionalmente estabelecidas. Na perspectiva gerativista, por contraste, a estrutura argumental de um predicado não é convencionalmente atribuída, mas antes descoberta. Um verbo como 'andar', por exemplo, se preenchido por um sintagma preposicional do tipo "como um felino", assimilará essa estrutura na posição de adjunto. E, nesse caso, esse adjunto funcionará como adjunto adverbial. Podemos, assim, parafrasear a sentença resultante da operação de adjunção ("João dança como um felino") como" João dança felinamente". Conhecemos atualmente, graças aos estudos gerativistas, várias características formais das línguas naturais como, por exemplo, que em todas as línguas naturais conhecidas existem poucos predicados com quatro argumentos. Essa descoberta, assim 
como a estrutura argumental do verbo acima mencionado, são tópicos de pesquisas empíricas, tópicos que não podem ser decididos por convenção, pois é assumido que as regras composicionais são impostas pela faculdade da linguagem.

Do ponto de vista formal, a forma lógica3, LF, promove a interface entre sintaxe-semântica, um mapeamento entre estruturas. Segundo Cook, e Newson (2007), a LF é análoga (mas não equivalente) à 'sintaxe lógica' usualmente empregada em semântica formal. A LF é responsável pela interpretabilidade das sentenças. Riemdikj e Williams afirmam que a LF fornece uma subteoria mínima do significado. Com efeito, vários fenômenos linguísticos (como anáfora, escopo de quantificadores, papéis temáticos etc.) podem ser sistematicamente tratados nessa estrutura. É lícito afirmar que a LF trata de relações internas, relações intra e inter sentenciais. A LF não determina ou prediz a propriedade 'significado' associado à uma sentença $\mathrm{S}$, apenas explica motivações possíveis, padrões da faculdade da linguagem que influenciam a interpretação de relações estruturais, sintático-semânticas. Em suma, a LF é uma condição necessária à competência semântica dos falantes. Parece razoável esperar que uma explicação formal pode oferecer uma explicação estrutural, esquemática, sobre as propriedades sintático-semânticas das línguas naturais.Essa explicação certamente não esgota o estudo dos fenômenos semânticos, mas parece mais adequada à investigação naturalística empreendida pelo Programa Gerativista, mesmo porque é uma noção técnica que possui força explicativa dentro desse programa de investigação.

2.2. Prioridades metodológicas: antes significado que verdade.

Em "Meaning Before Truth", Pietroski defende as 
seguintes teses:

(i) Sentenças não possuem condições de verdade. Apenas asserções possuem condições de verdade;

(ii) Uma teoria semântica deve ocupar-se das condições sintáticas e lexicais que restringem, mas não determinam, condições de verdade.

A tese (i) indica que o significado em linguagem natural não deve ser identificado com condições de verdade, pois 'ser verdadeiro' é uma propriedade que se aplica asserções e não a sentenças. Tal atribuição depende, argumenta Pietroski, de um numero massivo de fatores intervenientes, que não são indicados pelas propriedades internas de $\mathrm{S}$ e que não podem ser formalmente rastreados, pois a interação se dá entre o significado da sentença (seu potencial semântico) e inúmeros outros fatores não codificados na sentença. Pietroski defende (ii) afirmando que, embora a teoria do significado deva ser concebida como uma teoria da compreensão linguística (i.e, uma teoria sobre habilidades humanas específicas), não é evidente que essa teoria deva ou possa ser criada em termos de uma teoria da referência, dado que a compreensão linguística surge como efeito da interação de um conjunto massivo e heterogêneo de elementos. Logo, existem obstáculos consideráveis (talvez insuperáveis) que as teorias semânticas extensionais precisam enfrentar. Por outro lado, argumenta, parece claro que o estudo sistemático do significado não pode ser dissociado do estudo da sintaxe e que pode beneficiar-se dele. Em suma, a tese (ii) sugere uma revisão e dos objetivos e uma re-orientação dos métodos usualmente empregados em semântica formal (mas não o abandono desses métodos).

$\mathrm{O}$ autor inicia o artigo afirmando que sentenças possuem indicadores de condições de verdade e que palavras, por sua vez, possuem propriedades intrínsecas como propriedades fonéticas e lexicais. O significado de $\mathrm{S}$, prossegue, é lexicalizado de maneira tal que combina-se com certos itens (e não outros) . Essas combinações 
lexicais restringem, sem determinar, condições de verdade. Pietroski afirma, acertadamente, que existem interações sutis entre léxico e princípios composicionais, mas não a determinação do significado por estes últimos. Essas propriedades são, na expressão de Pietroski, rastros de como os seres humanos compreendem sentenças. Essas propriedades são teoricamente relevantes para a teoria gramatical gerativista e em uma teoria semântica que nela se baseie, conclui.

Creio que o seguinte exemplo pode esclarecer a tese defendida por Pietroski: no gerativismo, os traços linguísticos são divididos em dois tipos: traços não interpretáveis i.e., informações pertinentes apenas para o componente computacional (ex: o expletivo "it" em "it rains" não recebe atribuição de papel temático) e traços interpretáveis, isto é, informações legíveis, interpretáveis pelos outros sistemas da mente (ex: o traço morfológico de plural é interpretável, porque a pluralidade traz informações pertinentes à interpretação semântica ${ }^{4}$ ). Esse traço seria uma das 'pegadas' ou 'rastros' que o sistema computacional (a faculdade da linguagem) imprime na competência semântica dos falantes-ouvintes.

O ambiente certamente é responsável por certos aspectos da estabilidade intersubjetiva no que diz respeito ao uso de expressões linguísticas, o uso que os agentes cognitivos fazem da língua para referirem-se ao ambiente que os circunda. Todavia, argumenta Pietroski, teorias semânticas podem e devem lançar mão de abstrações acerca de várias diferenças individuais e ambientais, pois o idioleto em comum é condição necessária, mas não suficiente, para a estabilidade linguística. Além disso, acrescenta, a compreensão e produção dos falantes-ouvintes pressupõe um conhecimento internalizado que vai além das evidencias de que eles dispõe efetivamente. Dito de outro modo: os seres humanos compartilham uma biologia que impõe restrições ao modo como inputs linguísticos são interpretados.

É importante destacar que isso não equivale a admitir que sentenças em linguagem natural são uma contraparte de fórmulas bem formadas de um cálculo lógico. A semântica, dentro do programa 
gerativista, está relacionada antes à noção de inteligibilidade gramatical do que ao conceito de interpretação semântica modeloteorética. Daí a diferença entre o famoso par de sentenças (1) e (2) ${ }^{5}$ :

(1) Ideias verdes dormem violentamente.

(2) * Dormem verdes coloridas furiosamente ideias.

A sentença (1) é inteligível (embora exótica). É possível associar uma interpretação a essa sentença, metaforicamente. Isso é possível porque (1) segue princípios formais regidos pela LF, não porque há uma forma lógica, em lógica de predicados, subjacente a ela. Podemos traduzir nossa intuição semântica e converter a sentença (1) em uma sentença formal $x$ éuma id éia verde $\rightarrow x$ dorme furiosamente

$$
\forall x i
$$

. Isso não significa que essa interpretação lógica seja uma condição subjacente, necessária à interpretabilidade dessa sentença. A sentença (2), por contraste, não é inteligível. A interpretação de (1) pode ser enriquecida, à medida que acrescentamos mais informações sobre a sua LF. O importante é que as características lexicais fornecem certas condições de legibilidade, geram expressões interpretáveis.

Que tipo de entidade é uma idéia verde furiosa? Assumindo a leitura extensional de 'idéia verde furiosa', como distingui-la de construções linguísticas como 'cachorro peludo furioso'? Parece claro, como argumenta Pietroski, que predicados em linguagem natural não têm condições de satisfação bem definidas. Predicados em linguagem natural têm significados flexíveis, que não podem ser caracterizados funcionalmente sem uma boa dose de abstração ou simplificação.

A princípio, não vejo problema nesse tipo de simplificação. Definições formais servem para formular os termos de uma teoria, a partir da qual da qual é possível 
desenvolver um programa de investigação. Contudo, me parece imprescindível notar que sempre é possível tratar certos fenômenos linguísticos formalmente, quando o semanticista faz uso de algumas abstrações, quando toma certas liberdades. O problema não é esse. O problema é inteligibilidade dessas manobras, saber enfim o que por que essas manobras interessam. Ao traçarmos uma analogia com a história dos modelos sintáticos formais do gerativismo, é possível perceber, claramente, que as teorias sintáticas formais forneceram subsídios para a elaboração de teorias psicolinguísticas sobre como se dão, efetivamente, os padrões de processamento sintático das sentenças em linguagem natural. No entanto, como é sabido, as predições projetadas por vários modelos formais (como modelo da complexidade derivacional, por exemplo) foram falseados por experimentos empíricos, o que levou, em alguns casos, ao abandono desses modelos. Essa parece ser uma postura razoável em relação ao repertório formal. Por que tratar a maquinaria semântica de forma diferente? Por que é preciso admitir, por exemplo, que nomes em linguagem natural são uma contraparte de constantes lógicas, de elementos criados em uma linguagem estipulada, formal?

Pietroski sugere a adoção de uma medida provisória: pede que admitamos, para fins de análise, que sentenças estão associadas a valores semânticos. Eis o argumento: Ao construir uma teoria, é possível parametrizar as questões empíricas. A tarefa central do semanticista consiste em descrever e explicar os fatos. Sendo assim, é lícito esperar que ele faça uso das teorias extensionais disponíveis. A medida que isso for sendo feito descartar-se-ão abordagens e teorias.

Ou seja, uma coisa é a postulação de valores semânticos como construtos teóricos; outra coisa é afirmação de que existe uma semântica extensional subjacente à linguagem natural. Não se trata, pois, de impugnar teorias semânticas extensionais. São aparatos técnicos fundamentais. Isso não dever conduzir o 
semanticista a adotar uma visão distorcida sobre a natureza e a fonte dos fenômenos linguísticos. Em geral, admite-se que as restrições vero-condicionais determinam as regras de interpretabilidade das expressões linguísticas. Pietroski sugere outra direção: expressões linguísticas delimitam (embora não determinem) certas restrições à atribuição de condições de verdade intuitivas.

É possível afirmar que 'referência', 'extensão', 'verdadeiro' são termos técnicos e é possível ainda, como Chomsky, questionar a utilidade explanatória desses termos. Antes de empregá-los, talvez seja mais apropriado esclarecer o lugar e o pape deles dentro da investigação da semântica das línguas naturais. Segundo Chomsky (), as noções fundamentais usualmente empregadas em semânticas extensionais não podem ser tomadas como princípios explanatórios de base para a elucidação de fenômenos linguísticos, pois esses princípios são, na verdade, construtos teóricos sintaticamente articulados. A faculdade da linguagem, por contraste, é composta por características internas: os traços fonéticos e semânticos; os itens lexicais, formados a partir da combinação dessas propriedades e as expressões linguísticas complexas. Do ponto de vista estrutural, os itens lexicais nada mais são do que conjuntos de traços fonéticos e semânticos; é sobre esses traços que o sistema computacional (S-C) se aplica, gerando expressões lingüísticas. $\mathrm{O}$ sistema computacional seleciona itens do léxico e confere a esses itens uma forma fonética e uma forma lógica. Cada expressão gerada corresponde a um par legível em PF e interpretável em LF. Assim, a sentença "João ama Maria", por exemplo, corresponde ao par [PF,LF], respectivamente: uma descrição fonética estrutural (i.e. uma sequência ordenada de sons), sintática (i.e. uma estrutura hierárquica de constituintes, responsável pela concatenação das palavras) e semântica (ex.. atribuição de papel temático etc.). Em suma, a teoria gramática fornece a representação fonético- 
semântica do léxico.

Dadas essas considerações, parece razoável admitir que uma teoria semântica associe expressões de sua metalinguagem a valores valore semânticos. Mas disso não se segue que o semanticista deva assumir que as expressões linguísticas (da linguagem objeto), representadas pela metalinguagem, denotem esses valores semânticos. Em suma, o valor semântico (0/1, $\mathrm{V} / \mathrm{F}$ ) corresponde ao valor associado a um termo dentro de um formalismo semântico. O significado de uma expressão linguística não coincide com e não e determinado pelo valor semântico a ela associada na metalinguagem.

É possível vislumbrar com maior clareza a proposta de Pietroski: trata-se de uma teoria sobre certo conhecimento tácito dos falantes-ouvintes. Ele direciona a investigação semântica ao estudo do que é chamado de "potencial semântico": trata-se de um tipo conhecimento semântico esquemático, tênue. Creio que é possível traçar certa analogia entre a proposta de Pietroski e o problema da aquisição da linguagem: dado que as línguas naturais são compostas por vários níveis de articulação, para cada nível de articulação existirá um subconjunto de problemas específicos. Para resolver cada um desses problemas, em cada nível de análise (fonológica, morfológica, sintática etc.), é necessário explicar as propriedades disponíveis, o que as crianças extraem dessas propriedades e como elas o fazem. Se todas as crianças de uma comunidade linguística convergem na forma como processam inputs linguísticos, o problema a ser explicado, o mistério a ser decifrado, consiste em explicar como isso ocorre, apesar das diferenças interpessoais e da variação ambiental, dialetal, cultural etc. Na teoria semântica proposta por Pietroski, os problemas são análogos: cumpre saber o que os falantes-ouvintes sabem (o formato da Língua-I), o input que eles recebem e que recursos a faculdade da linguagem e os sistemas de interface disponibilizam.

\section{Conclusão}


Creio que agora é possível fazer um resumo sinóptico do programa proposto por Pietroski. Isso será feito a partir das perguntas lançadas anteriormente. Recapitulando:

(P) Qual o objeto de estudo da semântica formal?

\section{A relação entre competência linguística internalizada e competência semântica.}

Ou seja, trata da relação entre estados estáveis de uma faculdade mental que opera de acordo com certos princípios (e que refletem aspectos inatos, biologicamente determinados) e sua interface com certa capacidade disposicional e internalizada dos falantes. A faculdade da linguagem permite aos falantesouvintes que articulem os diferentes níveis oferecidos pelos inputs linguísticos e fornece instruções básicas para que reconheçam o potencial semântico de itens lexicais, sentenças etc. É essa capacidade disposicional que nos permite reconhecer, muito rapidamente, que 'Maria dolmeia constantemente' é uma sentença, embora não saibamos exatamente qual o seu significado. Ou seja, identificamos certas relações estruturais, embora não necessariamente as identifiquemos conscientemente, reflexivamente. É esse dispositivo estável que nos possibilita refletir sobre essa sentença e especular que o termo 'dolmeia' é, provavelmente, um verbo.

(P1) Qual o formato e escopo de uma semântica formal adequada à descrição e explicação do significado em linguagem natural?

II. O formato deve consistir em uma adaptação do aparato formal disponível nas teorias sintáticas aos recursos de uma 
teoria semântica semi- composicional. Quanto ao escopo, abrangerá questões teoricamente relevantes dentro de um programa de investigação internalista. Estão incluídos fenômenos como ambiguidade, papéis temáticos, gramaticalidade, paráfrase, hiperonímia, hiponímia, antonímia, homonímia etc.

O programa proposto por Pietroski parece bastante flexível quanto ao aparato que uma teoria semântica deve incorporar. Como semanticista, ele sabe que não pode determinar, a priori, qual o será o melhor aparato. $\mathrm{O}$ 'melhor aparato' será aquele que conseguir explicar os fenômenos em análise. Dado seu compromisso com o programa gerativista, cumpre seguir a investigação a partir postuladas pelo programa (no momento, as ferramentas fornecidas pelo Programa Minimalista). No fundo, não interessa determinar o objeto de estudo da semântica, ma sim a maneira de abordar perguntas teoricamente relevantes.

Parece claro que Pietroski está comprometido em elaborar uma teoria linguística. Ou seja, ele almeja uma teoria que cumpra as condições (C1)-(C2). A utilidade de uma idealização formal depende das questões que ela nos permite levantar, dos fenômenos que o aparato formal permite elucidar. Que fenômenos semânticos o aparato lógico-formal permite elucidar? Considere a seguinte sentença:

(1) Toda mãe ama seu o filho.

Em termos gramaticais, o pronome possessivo 'seu' é uma palavra que substitui um nome. Adotando esse critério, o pronome em questão retoma o sintagma nominal mais próximo, a saber, 'Toda mãe'. Assim sendo, (1) equivaleria à seguinte paráfrase:

(1') Toda mãe ama o filho de toda mãe. 
O que não parece ser o caso. Sabemos, intuitivamente, que (1) possui outra leitura: toda mãe ama cada um de seus filhos (e não os filhos de todas as outras mães). Todavia, se admitimos que as línguas naturais possuem variáveis, a sentença (1) pode ser parafraseada, em lógica de primeira ordem, como: (1") $(x$ émãe $\rightarrow$ xamao fil hode $x))$.

Considere agora o seguinte exemplo:

(2) Minha namorada gosta do meu carro.

Sabemos que o significado do pronome possessivo, nas duas ocorrências acima, não é o mesmo. 'Meu carro' sugere uma relação de posse, uma relação que não é idêntica aquela expressa por 'minha namorada'. Esse conhecimento depende do reconhecimento de certas regularidades sociais. Nesse caso, as relações intra-sentenciais não nos dizem muito. Nesse caso, o formalismo semântico não é capaz de elucidar o fenômeno. Até onde posso ver, esse é um padrão recorrente: alguns fenômenos semânticos parecem estar relacionados à interface entre léxico e sintaxe (O caso (1) é um exemplo de ambiguidade de escopo). Nesses casos, o formalismo é não só bem vindo, como é imprescindível. Em casos mais complexos, o uso do formalismo é discutível.

Quanto aos princípios contextualistas, temos: (A)-(C) são coerentes com a tese defendida por Pietroski de que a compreensão linguística surge como efeito da interação de um conjunto massivo e heterogêneo de elementos. $\mathrm{O}$ mesmo pode ser dito do princípio (D) pois, como visto, Pietroski argumenta que predicados em linguagem natural são vagos e sensíveis ao contexto. Contudo ele acrescenta a seguinte pergunta: por que devemos apostar que é possível formular uma teoria verocondicional capaz de acomodar todos os aspectos de 
dependência contextual? A proposta de Pietroski também é coerente com o princípio (E). Mas o que se segue dessa importante constatação? Seria a semântica espécie de 'pragmática fossilizada'? Pietroski responde que não. Ele sustenta que o fato de que uma asserção tem certas condições de verdade é um efeito massivamente interativo. Contudo, ele acrescenta que o significado da sentença (seu potencial semântico) é um desses fatores, um componente do somatório. Eis então a desacordo metodológico entre o programa de Pietroski em relação ao contextualismo: é possível isolar o significado (potencial semântico) e teorizar a seu respeito. A delimitação da investigação é necessária, porque existem aspectos da comunicação que não são formalmente tratáveis. Termos como 'verdadeiro' ou 'satisfazível' são termos técnicos que podem caracterizar de maneira equivocada essas questões.

Creio que a origem desse desacordo metodológico resida, em parte, de um pressuposto comumente aceito em filosofia da linguagem (e creio que aceito pelos contextualistas), mas pouco discutido: a sintaxe estuda sentenças, a semântica estuda proposições. Ou seja, a semântica trata de proposições e suas relações com sentenças da linguagem natural. Questões significativas sobre a semântica nunca surgiriam na sintaxe, pois ela consistiria em uma mera descrição do sistema linguístico. Além disso, pressupõe-se que fazer semântica é algo muito diferente, muito distante, de fazer sintaxe.

Assim sendo, podemos examinar a resposta de Pietroski à pergunta:

(P2) Como formular regras capazes de sistematizar fenômenos de alta dependência contextual? Em que medida é possível incorporar as críticas contextualistas em uma teoria semântica formal?

Pietroski está de acordo com as motivações contextualistas. Concorda que o que interessa a uma teoria semântica é explicar as capacidades cognitivas dos seres 
humanos. Contudo, para Pietroski, o programa de investigação semântica deve estar voltado a perguntas como: por que os seres humanos não interpretam sequências sonoras de certas maneiras? Como as crianças aprendem o significado das palavras, como aprendem a combiná-las e atribuir-lhes significado? Por que percebemos, muito rapidamente, propriedades e relações linguísticas como ambiguidades, contradições, acarretamentos, anomalia, papéis temáticos, impossibilidades e possibilidades de interpretação etc.? Em suma, para Pietroski, a tarefa consiste em explicar como o significado restringe (sem determinar) o uso. Seria uma perspectiva mais próxima àquela definida por Mumford e Anjum (2011) como disposicionalismo: palavras dispõem os falantes em direção a certos significados potenciais, embora esses significados só se atualizem em contexto.

Existem razões para crer que Chomsky está correto quando afirma que não faz sentido investigar os princípios de organização do sistema visual a partir da análise de práticas e costumes sociais. No que diz respeito à semântica, parece pertinente questionar por que uma semântica massivamente parametrizada é preferível a uma semântica mais simples, mais esquemática.

A abordagem naturalista, observa Chomsky (1980b), conduz a certo tipo de conhecimento, muito especifico e idealizado, sobre o mundo. É um tipo particular de investigação, que se aplica sobre domínios muito restritos, em que é possível lançar mão de simplificações e generalizações capazes de modelar, ainda que imperfeitamente, certas regularidades não fortuitas. A semântica, nessa perspectiva naturalista, é o estudo sobre de certas propriedades formais e estruturais encontráveis nas línguas naturais e sua interface com a competência semântica dos falantes. É necessário o emprego de uma metalinguagem técnica que permita a abstração e simplificação suficientes para que os problemas possam ser parametrizados. 
Com isso, espera-se que será possível distinguir, por exemplo, os fenômenos formalmente caracterizados na teoria de fenômenos idiossincráticos (como variações dialetais, culturais ou individuais). Essa não parece ser a tendência atual das teorias semânticas, como reconhece Pietroski ${ }^{6}$ :

Claro que alguém poderia querer uma abordagem sobre como tudo isso está relacionado - pensamento, comunicação, significado, referência, verdade, confirmação, átomos, constelações, louvor, condenação e tudo mais. E é possível definir 'Linguagem' de forma tal que uma Linguagem teria as propriedades necessárias para que tudo isso estivesse relacionado conforme o previsto. Mas não se segue que existam Linguagens, muito menos que elas incluam as línguas naturais faladas.

Aos que apostam na exequibilidade desse tipo de empreendimento, desejo boa sorte. Ela será imprescindível.

\section{Referências Bibliográficas}

CAPPELEN, Herman \& LEPORE, Ernest. Insensitive Semantics. A Defense of Semantic Minimalism and Speech Act Pluralism. Blackwell Publishing, 2005.

CHOMSKY, Noam. Aspects of the Theory of Syntax. Cambridge: M.I.T., 1965.

Reflexões sobre a Linguagem. São Paulo: Cultrix, 1980a.

Rules and Representations. New York: Columbia University Press, 1980b.

COOK, Vivian \& NEWSON, Mark. Chomsky's Universal Grammar. An Introduction. Malden, MA: Blackwell Publishers, 2007.

LECLERC, Andre. Princípios para uma Semântica das Línguas Naturais: Os Clássicos e os Novos. In: Perspectiva Filosófica. UFPE, v. 2, 2009, p. 11-35.

MARCUS, Gary. Kludge: A Construção desordenada da Mente Humana. Campinas, SP: Editora da UNIÇAMP, 2010.

MUMFORD, Stephen \& ANJUM, Rani. What We Tend to Mean. In: Norsk Filosofisk Tidsskrift 1 (46), 2011, p. 20-33.

NEGRAO, Esmeralda Vailati. A faculdade da linguagem e os sistemas de interface: as relações entre a sintaxe e a semântica. In: DELTA, vol. 
23, 2007, p.43-64.

PIETROSKI, P. M. The Character of Natural Language Semantics. In: BARBER, A. (ed.). Epistemology of Language. Oxford: O.U. P., 2003b, p. 217-256.

. What Meanings Probably Are Not. (Given Autonomous Syntax). (Não publicado), 2004.Disponível em: http://web.eecs.umich.edu/ rthomaso/lpw04/pietroski.pdf. Acesso em: outubro de 2011.

. Character Before Content. In: THOMSON, J. \& BYRNE, A. (eds.). Content and Modality: Themes from the Philosophy of Robert Stalnaker. Oxford: O.U.P., 2006, p. 34-60.

. Meaning Before Truth. In: PREYER, G. \& PETERS, G. (eds.). Contextualism in Philosophy. Oxford: O.U. P., 2005, p. 253-300.

PIRES DE OLIVEIRA, Roberta. Formalismos na lingüística: Uma Reflexão Crítica. In: BENTES, A.; MUSSALIM, F. (eds.). Introdução à Linguística: Fundamentos Epistemológicos, vol. 3. São Paulo: Cortez, 2009, p.219-250.

SOAMES, Scott. Philosophy of Language. Princeton, Princeton University Press., 2010.

TAYLOR, Charles. Philosophical Papers. Human Agency and Language. Cambridge University Press, 1985.

\section{Notas}

1 Para um bom resumo delas, ver Marcus (2010), cap. 5.

2 Idem, pp.23-29.

3 Forma lógica, em sintaxe gerativa, não significa sentença formal em lógica de predicados de primeira ordem, mas sim a conversão dos itens lexicais em descrições estruturais que explicitam exigências categoriais e semânticas de cada item.

4 NEGRÃO (2007).

5 A partir de Chomsky (1965) sentenças como (1) passam a ser consideradas agramaticais, por ferirem princípios que governam a atribuição dos papéis temáticos. O exemplo é aqui utilizado em caráter ilustrativo.

6 Of course, one would like an account of how it all hangs together-tought, communication, meaning, reference, truth,confirmation, atoms, constellations, praise,condmnation, and everything else. And one can define 'Language' so that a Language would have the properties needed to make all hang together in some envisoned way. But it doesn't follow that there are Languages, much less that they include natural spoken languages. Pietroski (2005), p.281. Tradução de minha autoria. 